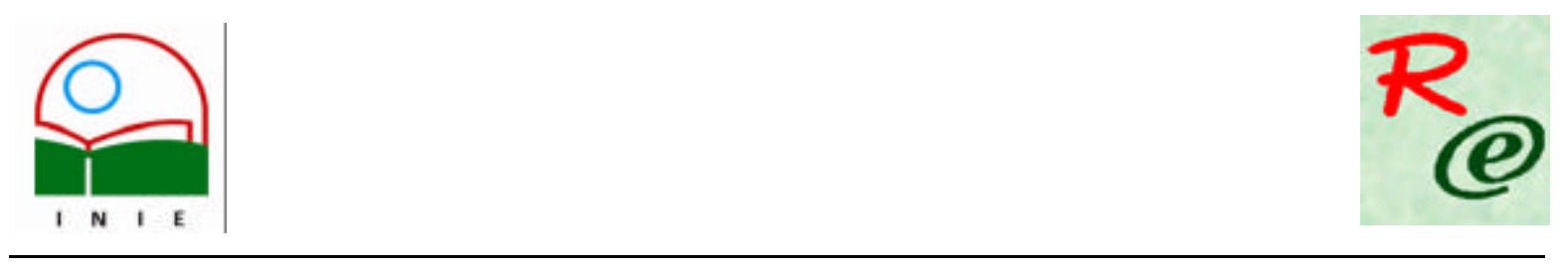

Actualidades Investigativas en Educación

Revista Electrónica publicada por el

Instituto de Investigación en Educación

Universidad de Costa Rica

ISSN 1409-4703

http://revista.inie.ucr.ac.cr

COSTA RICA

\title{
HACIA UN ESTILO DISCIPLINARIO DESINTOXICADO
}

TOWARDS A DETOXIFIED DISCIPLINARY STYLE

Volumen 9, Número 1

pp. $1-30$

Este número se publicó el 30 de abril 2009

Osvaldo Murillo Aguilar

La revista está indexada en los directorios:

LATINDEX, REDALYC, IRESIE, CLASE, DIALNET, DOAJ, E-REVIST@S,

La revista está incluida en los sitios:

REDIE, RINACE, OEI, MAESTROTECA, PREAL, HUASCARAN, CLASCO 


\title{
HACIA UN ESTILO DISCIPLINARIO DESINTOXICADO TOWARDS A DETOXIFIED DISCIPLINARY STYLE
}

\section{Osvaldo Murillo Aguilar}

\begin{abstract}
Resumen: En este ensayo se analizan desde la Orientación, los principales estilos que presentan las docentes y los docentes para el manejo de la disciplina en las aulas y los centros educativos.

Para dicho análisis se utilizaron los enfoques de intervención cognitivos, de la Terapia Racional Emotivo Conductual y el Cognitivo - Conductual con el fin de exponer cuáles podrían ser algunas de las ideas o creencias centrales más notables en la gestión de la disciplina. Dichas ideas son abordadas en el ensayo como "tóxicos cognitivos" que pueden ser debatidos y modificados a fin de conseguir un mejor y más sano estilo para el manejo de la disciplina y por lo tanto un clima escolar más armónico.

Por último, para las profesionales y los profesionales en Orientación puede ser un criterio más para abordar el tema en sus instituciones con sus compañeras y compañeros docentes.
\end{abstract}

Palabras clave: ESTILOS DISCIPLINARIOS, CONVIVENCIA ESCOLAR, IDEA IRRACIONAL

Abstract: This essay analyzes from a Guidance perspective the main styles used by teachers to handle discipline in classrooms and schools.

Cognitive intervention approaches were used with the purpose of showing what might be the major ideas or beliefs in the management of discipline. These ideas are conceived in the article as "toxic cognitions" that can be discussed and modified to learn a better style of discipline.

Lastly, for guidance counselors, it can be a resource for addressing the issue in their institutions with their fellow teachers.

Keywords: DISCIPLINARY STYLES, SCHOOL COEXISTENCE, IRRATIONAL BELIEFS

\section{Introducción}

La mayoría de las personas en a actualidad nos hemos visto expuestas a conductas violentas y a las transgresiones a las normas de convivencia, ya sea en espacios privados o públicos, circunstancias que de alguna manera no nos permiten establecer relaciones interpersonales armónicas y pacíficas, y por ende tener una mejor calidad de vida.

Ticenciado y Bachiller en Ciencias de la Educación con énfasis en
Orientación de la Universidad de Costa Rica.
Actualmente labora en el Instituto de Investigación en Educación
como facilitador en el Programa de Capacitación en Manejo de la
Disciplina para convivencia
Armónica en el aula, y como colaborador en la Red Latinoamericana
de Convivencia Escolar.

Dirección electrónica: osvaldo.murillo@ucr.ac.cr

Artículo recibido: 22 de octubre, 2008

Aprobado: 2 de abril, 2009 
La escuela por su parte no se escapa a esta realidad del contexto social, y de alguna manera se ve inmersa en una dicotomía complicada de resolver. Por un lado la sociedad cifra sus esperanzas en el sistema educativo como espacio privilegiado para mejorar la convivencia y por otro, las interacciones dentro de las instituciones educativas son fiel reflejo de lo que sucede fuera de ellas.

En medio de este predicamento en que se encuentran nuestros centros de enseñanza, es fácil comprender por qué el tema de la Convivencia Escolar es considerado por nuestras docentes y nuestros docentes como una prioridad.

No son pocas las maestras y maestros que expresan su frustración por no poder dar sus lecciones con fluidez, o su cansancio por resolver semana a semana casos de agresión o muchas otras faltas a las normativas institucionales. Al parecer muchas de sus fuerzas están más enfocadas en resolver conflictos de convivencia que en ocuparse de la metodología de sus lecciones.

Desde la Orientación la responsabilidad como profesionales de apoyo en las instituciones educativas en la temática de la disciplina y la convivencia escolar, demanda un análisis cada vez más holístico del asunto, que brinde mayores parámetros para intervenciones más eficientes.

Es por ello que para comprender con mayor profundidad el tópico del manejo de la disciplina y la convivencia escolar, que el presente ensayo tiene como finalidad:

1. Ofrecer una perspectiva desde la Orientación, del manejo de la disciplina en las escuelas, utilizando los enfoques cognitivos de intervención.

2. Exponer cuáles podrían ser algunas de las ideas o creencias centrales más notables en la gestión de la disciplina por parte de las docentes y los docentes.

La intención es ofrecer un documento de reflexión, profesional y personal, para quienes están involucrados directa e indirectamente en los procesos de educación en nuestras escuelas, y crear de esta manera un aporte más al análisis de dicha temática tan importante. 
Cabe aclarar que los ejemplos que se mencionan en este ensayo surgen de la experiencia del autor como facilitador del Programa Manejo de la Disciplina para la Convivencia Armónica en el Aula y el Centro Educativo, durante los años 2006 y 2007. ${ }^{3}$

\section{Percepción de las dificultades en la convivencia escolar}

Es común escuchar en varios centros educativos la necesidad imperiosa casi demandante de eliminar los conflictos escolares. De igual manera se busca desesperadamente, en libros de técnicas para manejar grupos, las estrategias recetarias para disciplinar a las estudiantes y los estudiantes de forma infalible.

Las preguntas que podrían desencadenar la discusión alrededor de este tema serían: ¿Quién dijo que teníamos que eliminar los conflictos escolares?

¿Quién dijo que la disciplina en el aula tenía que ser infalible?

Si analizamos ambas preguntas probablemente la respuesta cognitiva sería: NADIE, pero conductualmente seguimos buscando erradicar los conflictos escolares.

Tratar de eliminar el conflicto en la escuela es paradójicamente tratar de eliminar en los centros de enseñanza algunas posibilidades de crecimiento y aprendizaje. No es cuestión de vivir en la anarquía, es poder convivir también con el conflicto. Tal y como lo menciona Valverde, citado en Centros Territoriales de Recursos para la Orientación, Atención a la Diversidad, Interculturalidad y Convivencia de Castilla en España (2006:5), "educar para la convivencia no es renunciar a la existencia de conflictos sino saber enfrentarlos y superarlos positiva y efectivamente."

De alguna manera se ha impregnado en algunas y algunos docentes la idea de que "una clase en la que se presentan conflictos es una mala clase". Despegarse de esta idea lleva tiempo, pero es posible. Este tipo de pensamientos, van envenenando la forma en que perciben los acontecimientos cotidianos y por ende también las consecuencias emocionales

\footnotetext{
${ }^{3}$ Dicho programa está a cargo del Instituto de Investigación en Educación de la Universidad de Costa Rica bajo la responsabilidad de Carmen Cubero Venegas. 
y las respuestas conductuales ante ellos. Por esto y parafraseando a Riso (2008) se puede decir que estas ideas son tóxicos cognitivos y de esta forma se les denominarán en el ensayo.

Por lo anterior, en el desarrollo de este ensayo se abordarán algunas recomendaciones para iniciar un proceso de desintoxicación cognitiva, es decir un proceso que permita debatir esas ideas, necesario para iniciar cualquier acción que pretenda mejorar las interacciones en los centros educativos y el manejo de la disciplina.

Para continuar en este análisis, es bueno definir qué son las Ideas Irracionales, para posteriormente observar como estas pueden estar influyendo en la convivencia escolar, propiamente en el manejo de la disciplina.

Las Ideas Irracionales según Ellis, (2000) se presentan cuando las personas transforman sus deseos y preferencias, del mundo y de sí mismas, en demandas y exigencias que deben ser cumplidas y acatadas. Estas ideas conducen a las personas a consecuencias autoderrotistas o autodestructivas y por ende interfieren con la armonía escolar.

A manera de síntesis Ellis, (2000) por medio del concepto del ABCDE, explica que los acontecimientos $(A)$ que afrontan las personas, son evaluados por un sistema de creencias racionales o irracionales (B), y dependiendo de esta valoración experimentan una consecuencia emocional (C). Si esta evaluación es realizada por medio de Ideas Irracionales, es necesario realizar un debate (D) que confronte estas ideas con otras más racionales, y por ende más saludables y beneficiosas para su vida, y las ejerzan constantemente $(\mathrm{E})$.

Por ejemplo y retomando el caso anterior, ante la idea de que "una clase en la que se presentan conflictos es una mala clase", un docente podría sentirse sumamente frustrado pues tiene a su cargo una clase que cree no funciona e incluso es probable que por esta misma situación el rendimiento del maestro disminuya y se desmotive, pues también es posible que el docente asimile una idea de personalización, por ejemplo deduciendo que si la clase es mala el docente también. 
La raíz de tal frustración de alguna manera se relaciona con la idea de que una clase debe estar libre de conflictos y amenazas, lo cual no tiene el más mínimo argumento sólido, pues es prácticamente imposible que en un grupo donde interactúan entre 25 y 35 personas no se presenten conflictos.

Una posición más racional frente al conflicto nos la presenta Rozenblum (1998), al mencionar que los conflictos no son ni buenos ni malos en sí mismos, simplemente existen. Por ende, lo que determina si un conflicto ayudó al crecimiento o no de la convivencia (escolar particularmente) es el proceso que se llevó a cabo para solucionarlo. Por ello, no se trata de eliminar los conflictos, sería desgastarse en una tarea infinita, es más bien buscar la manera menos irracional de enfrentarlos, es decir más percibirles de una manera más objetiva para buscar alternativas de solución viables.

\section{Estilos de ejercer disciplina}

El modo de hacerle frente a los conflictos de la convivencia escolar es muy variado de ahí que existan diferentes formas de aplicar la disciplina en el salón de clases, lo que Baumrind, citada por Barba, et al. (2002) y Rabazo (1999) denominaron como estilos educativos parentales o como lo menciona De la Mora (2003), estilos de disciplina los cuales son:

\section{1) Estilo Autoritario 2) Estilo Permisivo 3) Estilo Democrático.}

Pasemos a reflexionar, sobre los diferentes estilos y su influencia en la convivencia escolar desde una perspectiva cognitiva:

\subsection{El Estilo Autoritario}

Según Baumrind (1971), este estilo de establecer disciplina se caracteriza porque se preocupa escasamente de las necesidades de las niñas, niños y jóvenes, y por el poco peso afectivo. Bajo este estilo se presenten privaciones, la coerción verbal y física.Este estilo de disciplina, según Noller y Callan (1991) presenta altos grados de control, y paradójicamente mayores posibilidades de aparición de conductas disruptivas. 
Generalmente según Barba, et al. (2002), el estilo autoritario tiende a resolver los conflictos unidireccionalmente, es decir, únicamente desde la figura de autoridad, sin considerar los aportes de las estudiantes y los estudiantes. Podría decirse que desde este estilo la disciplina es sumamente rígida e inflexible. Esta característica de inflexibilidad está estrechamente relacionada con una serie de ideas irracionales, o como se les denominará en este ensayo, parafraseando a Riso (2008), tóxicos cognitivos los cuales se revisarán a continuación.

\section{Tóxico 1. La supremacía de la Norma.}

Toda escuela, y más particularmente, toda aula necesita de una normativa, la cual según Fierro y Carbajal (2003), presenta los horizontes de comportamiento que se esperan y desean para los miembros de un grupo, además de los valores que se eligieron para convivir.

No obstante dentro de esta disciplina rígida, la normatividad deja de ser una propuesta de convivencia, tal y como lo propone Tuvilla (2005), y es colocada por encima de las necesidades de las y los integrantes del grupo, por decirlo de alguna manera, pasa de un papel secundario (pero importante) a uno protagónico.

La docente o el docente que se desenvuelve bajo este estilo de disciplina, se puede decir que se siente a gusto bajo la protección de La Ley del Aula. Es su Ley. Ella o el la establecieron, es inmodificable y bajo ninguna circunstancia negociable.

Una frase que ilustra a la maestra o maestro que tiene este estilo de disciplina es: "si en el reglamento está es porque así es", un claro ejemplo de pensamiento redundante, (es decir, la misma causa de la idea se convierte en su explicación y consecuencia), el cual denota que no existe el más mínimo interés de al menos cuestionar la normativa y saber las razones de por qué se aplica de esa manera.

No cabe la excepción a la regla en este esquema normativo, se podría decir que no se da el brazo a torcer, ya que es percibido por las docentes y los docentes del estilo autoritario como pérdida de poder y de fortaleza ante el grupo. Por tanto, se podría afirmar que desde este 
estilo las expresiones emotivas también se encuentran reprimidas, tal y como lo ilustra un ejemplo retomado por Cubero, Abarca y Nieto (1996:57):

"Un alumno le dice a su maestra: Estoy muy alegre. La maestra sigue escribiendo y no le responde"

Del mismo modo, bajo este estilo rígido la disciplina en el aula se puede clasificar como prohibitiva, ya que la mayoría de las normas están redactadas en términos de lo que NO se debe hacer bajo ninguna circunstancia. También en algunas ocasiones las normas llegan a contradecirse y otras veces la instrucción es un poco ambigua. Algunos ejemplos de estas normas observadas en los salones de clase, con sus respectivos cuestionamientos son:

a) No levantarse: la pregunta clave que cualquier estudiante se podría hacer es ¿y qué pasa si me levanto? o ¿tengo que quedarme sentado todo el día? Esta norma escrita por una docente no deja espacios para excepciones. Por ejemplo si el estudiante se levanta para aclarar una duda, ya faltó a la norma.

b) No andar de pie: ¿y cómo ando? Similar a la anterior pero más sencilla de debatir con el humor. ¡Eso quiere decir que puedo andar de rodillas por el aula o gateando!

c) En clase solo se habla del tema de estudio: ¿y cuándo puede el estudiante hablar de su vida personal? Esto subraya la característica de este estilo autoritario según Baumrind (1971), de la escasa preocupación de las necesidades de las estudiantes y los estudiantes. Probablemente la idea detrás de normas como esta es: "si les permito que se expresen pierdo el control de la clase", "la clase siempre debe estar bajo mi control", "muestro debilidad si les permito la libre expresión".

Ellis (2000) denomina a este tipo de ideas como Falacias de Control, donde la persona considera que debe estar en control absoluto de todo aquello que le rodea.

Las siguientes 2 normas se encuentran en la misma aula: (nótese la contradicción)

d) 1. Hablar en voz baja. 2. Permanecer en silencio. 
Ante ambas normas es difícil saber qué es lo que la docente quiere o espera de sus estudiantes.

e) Saludar alegremente y ser feliz: ambas son normas de clase encontradas en distintas escuelas. Pero con el elemento común de pretender normar una emoción. Si una niña o niño, un poco perspicaz le pregunta ¿maestra, y qué pasa si hoy no me siento feliz? ¡La norma sufre un colapso importante!

La disciplina rígida o autoritaria tiene un afán de control tan grande que en ocasiones por lo visto en estos ejemplos, no existen criterios claros para definir las normas, a partir de lo que se espera del estudiantado. La excesividad en la normativa según Baumrind (1971), reduce la autonomía de las personas. Es probable que existan estudiantes que se sienten aceptados por sus docentes, no por quiénes son, sino porque les dan gusto con las normas. Por lo tanto, antes de poner una norma es importante preguntarse ¿para qué sirve esta norma? ¿Es práctica?

Según Riso (2008) en ocasiones la norma supera la moral, dándole a esta una inflexibilidad incuestionable. Un ejemplo de ello, en ocasiones se presenta cuando las o los estudiantes asisten a la escuela con medias blancas y son sancionados por esto, aunque la razón para ello, sea que solo tienen un par de medias azules que, por ser invierno, no se han secado del todo. Otro caso es cuando en el reglamento dice que hay que sancionar con rebajo de 30 puntos en su nota a un estudiante por determinada conducta, y se hace sin considerar la negociación con el estudiante o sopesar que exista un verdadero arrepentimiento de su parte, por el error que cometió.

¿Acaso lo que se busca no es el aprendizaje y la corrección, o más bien será la sanción y el castigo?

\section{Tóxico 2. La defensa del Status Quo}

La forma en que se mantiene la disciplina autoritaria o rígida, es no hacer ajustes, se podría decir que vive de la costumbre. Esta resistencia al cambio denota la presencia de otra idea irracional como lo es pensar que la norma "si me ha servido antes, me va a servir ahora, 
¿para qué la voy revisar o cambiar?”Esto es claramente una trinchera contra el cambio, ya que la disciplina autoritaria, quiere permanecer siempre igual.

Cuando se proponen ideas novedosas para implementar en términos de disciplina es muy claro identificar a las personas que aplican la disciplina autoritaria, ya que suelen manifestar: "eso no va a funcionar". Otras y otros docentes, piensan igual, pero hacen el intento de aplicar las nuevas estrategias, sin embargo con el gran detalle de que aún no creen que vayan a funcionar, por lo que es común escucharles decir "yo probé y no funcionó". Evidentemente, tras esta última expresión, existe una clara profecía autocumplidora, de alguna manera ejercer este tipo de disciplina es una forma de auto-boicotear los esfuerzos por innovar y mejorar la convivencia escolar.

En parte este estilo de disciplina "intoxicada" o autoritaria, también cobija a las metodologías tradicionales resistentes al paso del tiempo y a los avances didácticos. No se quiere decir con esto que aquellas estrategias y técnicas que han sido muy efectivas halla que cercenarlas del quehacer educativo, simplemente es darse la oportunidad de cuestionar y evaluar su impacto en el manejo de la disciplina. Un ejemplo típico de la resistencia al cambio son aquellas y aquellos docentes que imparten lecciones con el mismo planeamiento de hace más de 10 años ¡Con las hojas amarillas por el paso del tiempo! Un maestro en una ocasión expresó:

"ya me sé la lección es la misma de todos los años... ¿para qué voy a hacer un planeamiento? Si lo hago va a ser solo para que me lo revisen lo supervisores"

Desestabilizar este muro cognitivo es algo complicado, en especial porque es bajo estas ideas que algunas y algunos docentes se sienten seguros en su labor. Se podría afirmar entonces, que la justificación para utilizar este estilo de disciplina en cierta forma, es el miedo. Es el temor de asumir nuevas posturas disciplinarias y perder el control de la situación en el aula, en especial porque es necesario descentralizar el control de la disciplina para reconocer que ésta es responsabilidad de todos los miembros de la comunidad educativa. La pregunta que podríamos hacernos para debatir este pensamiento podría ser: 
¿Qué tal si....? Por ejemplo: ¿Qué tal si este año el tema... lo abordamos diferente? ¿Qué tal si este año las normas las ponemos de común acuerdo en el aula?

\subsubsection{Tóxicos en la relación Docente - Estudiante}

En la disciplina autoritaria es notable la tensión existente en la relación docente - estudiante. Una relación básica para la convivencia escolar armónica es aquella en la que docente y estudiante, según lo menciona Tuvilla (2005), mantienen un intercambio basado en la cooperación y el apoyo mutuo, lo cual a la vez favorece conductas más adecuadas y mayor aceptación de las normas. Sin embargo esta relación en ocasiones se ve empañada por algunas situaciones que se alejan de la armonía como por ejemplo lo son:

\section{Tóxico 3. Catalogar y rotular}

Desde este estilo de disciplina es común escuchar las etiquetas que las maestras y maestros colocan a sus estudiantes prácticamente desde el inicio del curso lectivo: "este estudiante es perezoso",o se le define como: "el malcriado", "la irresponsable".

Se puede decir que el mismo afán de control de parte de la docente o el docente del estilo autoritario, les lleva a Catalogar o Rotular a sus estudiantes. Similar a cuando se ordena una repisa en un supermercado, desde el estilo autoritario, surge la necesidad de ordenar el aula por medio de las etiquetas, para saber de antemano donde están los más y los menos responsables, para saber como debo compórtame con ellas y ellos.

La idea irracional de Rotular según Riso (2006), consiste en asignar rasgos negativos globales a sí mismo y a los demás. No se señala un comportamiento o un pensamiento en particular, sino que se ataca a la persona como un todo. ¿Será lo mismo decir: "Faltó con una tarea" a decir, "Es una irresponsable"?

Por ello es importante cuando se llama la atención de estudiantes, hacerlo hacia su conducta perturbadora y no hacia la persona como un todo. Con frases por ejemplo como: "No me gustó eso que hiciste" o también "lo que dijiste no es apropiado y lastimaste a tu compañero". El peligro de las etiquetas es que estas, en especial en la edad escolar, podrían fácilmente convertirse en profecías autocumplidoras. Observemos esto con un ejemplo tomado de una observación realizada en una escuela ubicada en un barrio urbano marginal de la capital: 
En una ocasión durante una visita a un centro educativo, estaba realizando unas observaciones por los pasillos, cuando intempestivamente sale de su salón de clase una maestra evidentemente enojada, con una niña de su brazo derecho y en su brazo izquierdo su salveque. La niña un poco asustada no tenía más remedio que seguir a su maestra hasta que se topan de frente con una señora. La maestra de la niña le dice a esta señora, que resultaba era la madre de la niña, lo siguiente:

"tome señora llévese a esta carajilla ya no la aguanto es una gran vaga solo falta que yo escriba por ella, porque no le da la gana ni agarrar un lápiz a esta vaga..."

Esperando que la madre reaccionara ante tal afrenta contra su hija, la señora, más bien le contesta a la maestra: "Usted tienen razón esta mocosa es una gran vagabunda en la casa es igual..." La tomó del brazo y se la llevó.

En este ejemplo es muy factible que la etiqueta de "vaga" pueda convertirse en una profecía autocumplidora en la niña, es decir, interioriza esta idea como verdad y se comportará de manera que la creencia se reafirme; lo cual es más probable cuando dos de las figuras más significativas de su vida están de acuerdo en tal afirmación. Lo triste de esta etiquetaje, menciona Riso (2008) es que te dicen que estas mal pero no te dicen en qué estás fallando y mucho menos como corregirlo.

\section{Tóxico 4. No Soportantitis y el pensamiento catastrófico}

Para Ellis, citado por Naranjo (2004), "la enfermedad" del no soportantitis, es aquella donde la persona se queda estancada en la idea de que no es capaz de soportar o de resistir lo que le sucede.

El pensamiento catastrófico por su parte es identificable según Naranjo (2004) cuando la persona utiliza frases como por ejemplo "es terrible que esto me suceda", "es terrible que esto me esté pasando a mí..." La misma Naranjo (2004:138) menciona que "la persona queda atrapada en lo negativo, en lo catastrófico y en la exageración...quedan paralizadas por la desilusión que les provoca suponer o creer firmemente que las cosas no deberían ser como son". 
Estas ideas tras las cuales se atrinchera la disciplina autoritaria para no cambiar y ser más flexible, se observan en los salones de clase, cuando las docentes y los docentes, expresan que la situación con su grupo es lo peor que les pudo haber ocurrido en su vida y que no podría ser más terrible, que prácticamente no hay planes de intervención en disciplina que le puedan ayudar. Paulatinamente el grupo va percibiendo esta idea y se va generando en él el sentimiento de que la maestra o el maestro ya no tienen el control. Es cuando la posibilidad de un caos se asoma por la puerta.

Por otro lado, el No Soportantitis se refleja también en la resistencia al humor y a lo inesperado. Docentes con esta idea del No Soportantitis, unida a la disciplina autoritaria, no soportan, como dice el refrán: "ni que pase una mosca". Cualquier intento de risa es rápidamente aplacado.

La disciplina autoritaria está permeada de perfeccionismo, no hay cabida para el humor, indispensable para el establecimiento y mantenimiento de la convivencia escolar armónica, según se menciona en Centros Territoriales de Recursos para la Orientación, Atención a la Diversidad, Interculturalidad y Convivencia de Castilla en España (2006). Por ello se puede decir, que el humor es percibido como un culpable de que las reglas desaparezcan, y por ello es necesario evitarlo. La frase de las docentes y los docentes al respecto son: "En la clase se está serio o no se está, no hay medias tintas“. El peligro de estas ideas es que puedan transformarse conductualmente en actos agresivos. Observemos el siguiente caso ocurrido en una escuela de nuestro país:

En una ocasión una maestra terminó en un enfrentamiento físico con uno de sus niños. La situación se originó porque él no quería copiar la tarea de la pizarra, ante la insistencia de la maestra cada vez más alterada, el alumno le dijo que entonces le sacaba copia al cuaderno de un compañero, a lo cual la docente no accedió, la discusión entonces pasó al plano físico. La maestra sacudió al niño y este respondió con una patada y una posterior persecución por el aula.

Quizá el miedo a sentir que se pierde el poder y el control de la situación, fue lo suficientemente intenso en el caso anterior, como para desencadenar en tales conductas. Si 
la intención era que el alumno tuviera las indicaciones para la tarea, ¿por qué no permitir que la fotocopiara? La idea con la que se percibe el acontecimiento anterior tal vez fue:

"No puedo soportar perder el poder".

Por otro lado, encontramos también la idea de personalización, la cual según Riso (2006) consiste en que las personas creen que los demás tienen algo contra ellas, sin tener en cuenta otras explicaciones de los acontecimientos. Es importante que la docente y el docente comprendan que las conductas perturbadoras de sus estudiantes tienen una causa generalmente originada por la insatisfacción de alguna de sus necesidades más elementales, y no son actos contra su persona propiamente. Por el contrario pueden ser una forma de pedir ayuda.

En resumen la disciplina autoritaria se encuentra cognitivamente intoxicada porque:

1. Se coloca la normativa por encima del estudiantado.

2. Bajo ninguna circunstancia se aceptan excepciones a la regla.

3. Existe dificultad para establecer empatía con las estudiantes y los estudiantes.

4. No se fomenta la autonomía.

5. Las normas generalmente se dirigen a la prohibición, más que a la corrección, busca más la sanción que el aprendizaje.

6. Se presenta resistencia y temor al cambio.

7. Se resuelven los conflictos unidireccionalmente.

8. Se utilizan etiquetas: se dirige a la persona y no hacia sus conductas.

9. Se considera terrible y catastrófica la conducta del grupo.

10. Existe temor de perder el control.

11. Se personaliza las conductas perturbadoras del estudiantado.

\subsection{El Estilo Permisivo}

Este estilo de disciplina se caracteriza según Baumrind, (1971) por el escaso control ejercido y por responder excesivamente a todas las demandas, en este caso, de las estudiantes y los estudiantes. Su estilo comunicativo, es unidireccional y poco efectivo. Se considera que no 
es necesario establecer límites y existe temor al enfrentamiento, por ello siempre se cede ante las exigencias.

Según Baumrind (1971), quienes crecen bajo este estilo permisivo no desarrollan responsabilidad social.

Un claro ejemplo de lo anterior es un docente de secundaria que dijo una vez: "yo en mi aula no tengo normas"a lo que el resto de sus compañeros respondieron "ah, con razón..."

Continuando con el análisis desde la perspectiva cognitiva, la ausencia de normatividad o el escaso control, podrían tener sus raíces en las siguientes creencias irracionales, aunque es importante subrayar que no son los únicos tóxicos:

\section{Tóxico 1. Mis estudiantes tienen que quererme}

Para Beck (2000), existen una serie de creencias irracionales relacionadas con la necesidad de ser una persona aceptada y querida que incluyen temas como la falta de autoridad, falta de control, debilidad y falta de respeto hacia sí mismo, entre otros.

El temor de perder el cariño de las personas está muy presente en quienes tienen esta idea de sentirse amadas y queridas por todos. Por ejemplo, aunque se enojen posiblemente no lo expresen para no perder el afecto de la otra persona.

En el caso del estilo permisivo es posible que la docente o el docente no deseen establecer límites y control en el aula, para que sus estudiantes no le retiren su cariño y "confianza". En otras palabras, bajo este estilo de disciplina intoxicada, el deseo de toda docente y de todo docente de ser aceptado y querido por sus estudiantes, es convertido en una demanda que debe cumplirse.

Lo anterior es probable que desencadene en lo que menciona Naranjo (2004) como una serie de ideas irracionales sutiles, como por ejemplo el Merezco que... Esta idea podría reflejarse bajo el estilo permisivo como: "ya que soy tan bueno y condescendiente con ustedes, merezco que se porten bien". De alguna manera la disciplina permisiva espera que 
la buena conducta de las estudiantes y los estudiantes aparezca como consecuencia de la excesiva tolerancia de la docente o el docente.

Para De la Mora (2003), suprimir las normas y el evitarle a las niñas, niños y jóvenes enfrentarse al conflicto, les provoca no saber qué se espera de ellas y ellos, no les permitirá identificar las normas en los diferentes contextos en los que se desarrollen.

\section{Tóxico 2. Minimizar}

Otra idea relacionada con estilo permisivo de la disciplina, se encuentra en minimizar los acontecimientos negativos que suceden en el aula o el centro educativo. Un ejemplo concreto de minimizar, es cuando un par de estudiantes se golpean durante un recreo o se está frente a un claro caso de Bullying (matonismo o acoso entre pares), y la maestra o maestro reacciona diciendo: "es cosa de niños, ahorita pasa".

También se encuentra aquella situación en la que el salón de clases es casi un circo, pero para la o el docente no existe mayor conflicto.

De cierta forma, el mensaje es más que claro en ambos casos: es mejor evitar la confrontación con la situación problemática. Quien minimiza lo hace partiendo de una creencia irracional aún más arraigada y por ende más difícil de concienciar, como lo es: "soy incapaz de enfrentarme a estas situaciones de indisciplina”. A esto se suma la idea irracional que detalla Ellis (2000) de: "es más fácil evitar que afrontar responsabilidades y dificultades". No son pocas las veces que docentes manifiestan que es más sencillo dejar que las cosas sigan su curso que complicarse asumiendo una posición en la cual hay que seguir todo un proceso tedioso para aplicar consecuencias.

No se quiere afirmar con ello que se atenderán todas las quejas, pues en ocasiones son demasiadas y efectivamente acerca de eventos que no tienen el mayor impacto, como suele suceder por ejemplo en los años de preescolar, donde las niñas y niños buscan a su maestra para quejarse constantemente. Atenderlas todas y estar pendiente del más mínimo movimiento de las estudiantes y los estudiantes, más bien nos coloca en la idea de la Maximización, más relacionada con el estilo de disciplina anterior. Lo que se quiere decir es, que es importante evaluar los acontecimientos y darles la prioridad que requieren. 
Tóxico 3. Y qué si...

Para Riso (2006), en esta idea irracional la persona opina de manera oposicionista "y qué importa si ocurre o no aquello". Esta distorsión cognitiva es una forma de resistencia pasiva (el famoso: iqué me importa!). Por cierto muy relacionada con la idea anterior, es una forma de minimizar y evitar el conflicto. Por ejemplo: y qué si no puedo controlar el grupo! o también iy qué importa si no tengo normas en mi clase! Ante un adecuado debate racional, es decir, cuando se confronta a la persona ante la irracionalidad de sus creencias con los más firmes argumentos, es probable que una persona bajo el estilo autoritario pueda manifestar mucha agresividad, pero ante una o un docente del estilo permisivo, puede surgir su más marcada indiferencia.

En resumen la disciplina permisiva se encuentra cognitivamente intoxicada porque:

1. Considera que es mejor evitar los conflictos que enfrentarlos.

2. Existe temor de perder el afecto del estudiantado si se establecen límites y se aplican consecuencias.

3. El deseo de ser querido por las estudiantes y los estudiantes se ha transformado en exigencia.

4. Existe la idea de que por medio de la excesiva tolerancia se obtendrá el favor del grupo.

5. La normativa es prácticamente nula.

6. Puede presentar conductas de indiferencia hacia el estudiantado.

7. Se minimizan los acontecimientos o conductas de las estudiantes y los estudiantes.

\subsection{El Estilo democrático: Desintoxicando la disciplina}

La búsqueda de un punto de equilibrio es una tarea difícil de lograr, pero no es imposible. Una disciplina que permita ejercer control sobre ciertas situaciones sin ser autoritaria y que facilite libertad en el grupo sin llegar a ser permisiva, parecer ser el sueño de las docentes y los docentes.

Baumrind citada por Rabazo (1999) y Barba, et al. (2002), menciona la importancia de ejercer control desde una perspectiva más democrática. Este estilo de disciplina democrático se caracteriza por la negociación más que por la imposición. 
Bajo este estilo las normas son negociadas y además se explican las razones que dan fundamento a la normativa. Según Baumrind (1971), la disciplina democrática reconoce y respeta la independencia de la niña, niño o adolescente.

Parafraseando a Ceballos y Rodrigo (1998), en el estilo democrático se busca que las normas destaquen aquellos comportamientos positivos y esperables más allá de inhibir los no deseados. Por otro lado, aquellas normas que se establecen de parte del profesorado, se hacen tomando en cuenta las necesidades y capacidades de las estudiantes y los estudiantes. Para Barba, et al. (2002), la principal finalidad de este estilo es favorecer el logro de la autonomía en las personas.

Por su parte, De la Mora (2003) llama a este tipo de disciplina como ecuánime, porque favorece la justicia y una toma de decisiones más sensata en el salón de clase. Poner en práctica la disciplina democrática requiere, necesariamente, de lo que se podría denominar como "desintoxicación cognitiva" de parte de la docente y el docente, ya que no es posible separar la disciplina de quien la administra, en este caso del profesorado. Si bien es cierto, la disciplina y el establecimiento de una convivencia armónica es una responsabilidad compartida del profesorado y del estudiantado, la administración de la dsciplina recae en el primero.

En otras palabras, la disciplina no es quien posee las ideas irracionales, son las docentes y los docentes que la administran. Por ello, es necesario que como docentes analicemos, más que nuestro tipo de disciplina, nuestras ideas, para debatir aquellas que creamos nos impiden llegar al equilibrio. Ahora bien, si se considera que ya se está aplicando este estilo, también es importante la revisión cognitiva para redoblar esfuerzos, en ocasiones es conveniente sospechar sobre nuestro propio trabajo. En este proceso de desintoxicación de la disciplina para alcanzar el desarrollo del estilo democrático, se sugiere lo siguiente:

\section{Desintoxicante 1. Acéptese a sí mismo}

Es necesario para la aplicación de disciplina democrática que las docentes y los docentes reconozcan sus propias fortalezas y limitaciones. Que estén concientes de que su propia aceptación, como lo menciona Ellis (2000), no depende de sus éxitos o la estima de las Volumen 9, Número 1, Año 2009, ISSN 1409-4703 
demás personas, en este caso de sus estudiantes. No quiere decir esto, que no sean apreciadas las muestras de cariño del estudiantado, o que se tengan que despreciar las opiniones de los demás, sencillamente se trata de valorar la influencia de esto en nuestra vida, sin que lleguen a ser determinantes en el autoconcepto.

Considerando esto, es razonable querer ser apreciado por el estudiantado pero, no es una obligación que todas y todos me aprecien. Por lo cual, tampoco es necesario llevar los niveles de tolerancia al límite de la permisividad, pero tampoco al extremismo del autoritarismo.

Fortalecer la autoaceptación es una tarea de todos los días que requiere de poder echar un vistazo al interior de nuestro ser y hacer un repaso objetivo, algo así como un inventario personal, que indique tanto aquellas fortalezas que como docentes podrían conducirnos hacia un estilo más democrático, como también aquellas limitaciones que nos llevan más hacia un estilo autoritario o permisivo, y valorar qué tanto podemos modificarlas. Un pequeño esquema para realizar este inventario personal, de una manera sencilla puede ser el siguiente: 


\begin{tabular}{|c|c|c|}
\hline Tipo de disciplina & Tóxicos & Desintoxicantes \\
\hline \multirow{4}{*}{ Estilo Permisivo } & & \\
\hline \multirow{5}{*}{ Estilo Autoritario } & & \\
\hline Estilo democrático & & Conducta que deseo \\
adquirir
\end{tabular}

Es necesario recordar que poseer más o menos "tóxicos" no le hace bueno o malo, simplemente es la oportunidad de evaluar aquellas cualidades e ideas que intervienen en el manejo de la disciplina que realiza en el aula, para poder debatirles y clarificar aún más aquellas cualidades del estilo democrático que ya tiene o quisiera adquirir.

La idea de este inventario es hacer un repaso concienzudo de aquellas ideas que le sujetan a un estilo permisivo o autoritario y debatirles (desintoxicantes), para dar un salto a un efecto final o estilo democrático más saludable.

Desintoxicante 2. Abandone los extremismos y retome la flexibilidad normativa Como se ha analizado en el ensayo, ni el excesivo control normativo, ni la ausencia o escasez de normas, les permiten a las estudiantes y los estudiantes alcanzar su autonomía u autocontrol. 
Tal y como lo menciona Fernández (1998), las normas tienen la función de dar estructura a la interacción, de manera que en la convivencia escolar no se presenten la confusión, la incertidumbre y la ambigüedad. Las normas no son en esencia la disciplina, solo son un mecanismo más para su manejo.

De acuerdo con Fierro y Carbajal (2003), el comportamiento normativo del docente nos indica su oferta valoral. Es así como la supremacía de las normas sustenta la oferta valoral de algunas y algunos docentes solamente en contener los impulsos de sus estudiantes. Antes de mencionar algunas pautas sugeridas para el establecimiento de las normas en las aulas, desde el estilo ecuánime, hay que revisar lo siguiente:

a) Las normas no son infalibles: en ocasiones se vuelven obsoletas, o no aplican para una población estudiantil específica, y se requiere que sean revisadas periódicamente. De alguna manera hay que dar el brazo a torcer en este sentido, en especial cuando la sugerencia de revisar una norma procede de una 0 un estudiante basándose en argumentos 0 justificaciones.

b) No se tiene el control de todo por más normas que se establezcan: en oportunidades los imprevistos nos colocan "entre la norma y la pared", poder ser flexible en estas instancias no solo favorece un clima de justicia sino que además es liberador. Para muestra un botón: la norma de "ir al baño solo en el recreo", fueron muchas las docentes y los docentes que tuvieron que ser flexibles y permitirle a sus estudiantes ir al sanitario, eso sí con cierta regulación, ya que en ocasiones niños y niñas por no recibir este permiso tenían sus necesidades fisiológicas en el aula. Hay que recordar que la norma no está por encima de la moral ni del sentido común. Flexibilizarse ante las excepciones es parte del crecimiento hacia la disciplina ecuánime, y no por ello se va a caer el mundo.

Unas preguntas que podrían ayudar en caso de querer ser más "elástico" ante las normas, y que según Naranjo (2004) ayudan a evaluar las ideas irracionales son:

¿Qué es lo peor que podría ocurrir sí...?

¿Cuál sería el resultado sí...?

A las cuales podría sumársele ¿Qué haría o pensaría yo en el lugar de mi estudiante?

Volumen 9, Número 1, Año 2009, ISSN 1409-4703 
Ahora bien, una vez observados estos puntos, algunas recomendaciones para el establecimiento de las normas del aula son, según Acosta (2007):

- Permitir que el alumnado tenga un papel fundamental en la elaboración de las normas.

- Desarrollar actividades que ayuden a precisar los conflictos concretos y cotidianos del grupo (concretar 5 o 4 comportamientos que entorpecen la dinámica de clase).

- Establecer las normas claras y sencillas que regularán esos comportamientos.

- Asegurar que existan ambigüedad en las normas.

- Repasar y revisar periódicamente las normas: su utilidad y funcionalidad.

- Tener visiblemente las normas y sus respectivas consecuencias, positivas y negativas.

Según Acosta (2007, p. 22), "las normas, en vez de enumerar prohibiciones, deben recoger lo que hay que hacer. $A$ veces no es fácil formularlas en positivo, pero conviene hacer el esfuerzo".

También el mismo Acosta (2007, p. 16), afirma que "ningún listado de normas por más exhaustivo que sea puede impedir que surjan conflictos", pues como se mencionó al inicio es parte de la convivencia escolar. La anterior afirmación debate claramente la irracionalidad de la rigidez normativa del estilo autoritario y sus falacias de control.

Además, estableciendo la normativa con las pautas anteriores no habría por qué temer o pensar que las estudiantes y los estudiantes puedan sentirse agobiadas y agobiados por las normas, lo cual como se analizó anteriormente es una de las mayores dificultades que enfrenta el estilo permisivo. Esto porque el estudiantado asume las normas como la responsabilidad de un compromiso en el cual participó conciente y libremente, ya no se trata de una imposición.

\section{Desintoxicante 3. No pretenda ganar como sea}

Básicamente este desintoxicante cognitivo lo que pretende es que la docente y el docente se sientan en la libertad de darle la razón a sus estudiantes cuando estas y estos la tengan. ¿Cuántos conflictos se pueden evitar dando este pequeño pero gran paso? 
La disciplina no puede tornarse en una lucha de poder. Generalmente cuando esto sucede las docentes y los docentes gritan o en ocasiones hasta llegan a la agresión física de un estudiante, tal y como se ha mencionado anteriormente, por demostrar desesperadamente que no han perdido el poder o el control del aula. Sin embargo, el mensaje es más que claro cuando esto ocurre: ¡sí se perdió!

Una manera de prevenir estas situaciones es escuchar activamente lo que la otra persona tenga que decir, sin prejuicios y valorar todos sus argumentos. De esta manera se obtiene la información suficiente para poder darle razón o aplicar una consecuencia. En este proceso de comunicación es recomendable no utilizar "filtros mentales" en los cuales según Beck (2000), únicamente se atiende un detalle de la información, generalmente el negativo, el cual es probable que también se maximice. Esto es, como lo menciona Ellis citado por Riso (2006), aceptar la ambigüedad y la incertidumbre, saber y reconocer que existen cosas frente a las cuales no podemos hacer nada. Es admitir que la certeza es un mito para aprender a vivir con las probabilidades.

\section{Desintoxicante 4. Sospeche de su trabajo}

Dudar, en ocasiones, es una buena técnica preventiva para evitar seguir intoxicándose de rigidez cognitiva en el manejo de la disciplina en el aula, al mismo tiempo que se sigue mejorando en el estilo democrático.

Si como docente empieza a considerar que todas las estrategias que utiliza para el manejo de la disciplina son las adecuadas, que no existen conflictos de convivencia en su grupo, o que no necesita modificar su planeamiento pues su trabajo es muy eficiente, es necesario entonces que sospeche de su desempeño. Creer que el trabajo que se está elaborando es prácticamente genial y no necesita de revisiones, llega a estancar. Las posibilidades de crecimiento profesional disminuyen al igual que la capacidad de autoaceptación.

Según Ellis, citado por Riso (2006) es necesario que las personas que deseen crecer en su vida puedan experimentar cierta inconformidad sensata en lo que se hace, con el fin de encontrar la forma de mejorarlo, para poder escudriñar en sus propios conocimientos y sospechar de aquellas cosas que siempre se dan por correctas. Esto no quiere decir que no Volumen 9, Número 1, Año 2009, ISSN 1409-4703 
se deben tener opiniones o creencias, sino más bien darse el chance de cuestionarlas de vez en cuando, ya que de esta forma puede encontrase con nuevos criterios que reafirmen la idea o por el contrario le lleven a descubrir un error.

Las docentes y los docentes que no sospechan de su trabajo, son quienes persisten en el mismo planeamiento por años y en las mismas técnicas para el manejo de la disciplina, le tienen pavor a la tecnología, no se actualizan sobre su profesión y difícilmente asisten a una capacitación. La sospecha de nuestro trabajo es el primer paso para tener una actitud más abierta hacia el cambio.

\section{Desintoxicante 5. Asumir el cambio}

Bajo el estilo democrático es necesaria una actitud de apertura al cambio, a la innovación y a los retos.

En todo cambio, según Riso (2008), es normal cometer errores. El reacomodo que requiere cualquier cambio genera un poco de tensión, pero es parte del proceso de modificación. Cuando se varían estrategias para el manejo de la disciplina, "hay que pagar derecho de piso" como se dice popularmente. En las primeras de tanteo es natural equivocarse y querer regresar al estilo tradicional de mantener la atención del grupo, sin embargo la perseverancia en la tarea, puede producir el gozo de vivir un cambio, tanto por los resultados como por el hecho en sí de la innovación.

El cambio no empata con la disciplina rígida, ni con la permisiva porque atenta contra el Status Quo, contra aquello que ofrece "seguridad". La docente y el docente resistente al cambio, se ilustra claramente con el refrán que dice "más vale viejo conocido, que nuevo por conocer". El asumir riesgos y experimentar, según Riso (2006), es la única manera de descubrir lo que realmente se quiere hacer. Se aprende por ensayo y error. El fracaso en una nueva metodología educativa, no le hace mal docente, sino más bien alguien que busca la actualización y mejoramiento de sus técnicas de enseñanza, así fracase en el intento. 
Puede empezar este proceso de desintoxicación preguntándose, como lo menciona Naranjo (2004): ¿cuál sería el resultado en caso de cambiar mi manera de manejar la disciplina? ¿Qué le diría a una amiga que se encontrará en mi misma situación?

Posteriormente puede darse la oportunidad de vivir la experiencia de por un momento no dar el tema que llevaba planeado y escuchar los gustos, intereses y necesidades de sus estudiantes en "una mesa redonda". Definitivamente el cambio no solo nos acerca a un estilo democrático de disciplina, más desintoxicado de ideas irracionales, sino que hace de la experiencia educativa una experiencia más liberadora.

\section{Desintoxicante 6. Quite las etiquetas}

Las etiquetas o catalogar a las estudiantes y los estudiantes predispone la actitud ante ellas y ellos, y la forma en que se manejará la disciplina en el aula. A esto se le suma el peligro de que las etiquetas puedan llegar a ser profecías autocumplidoras.

Según Riso (2008), el rotular es un claro "infantilismo cognitivo", es haberse quedado en la etapa preoperacional de Piaget, donde los juicios no miden intenciones y mucho menos el contexto socio-cultural para tomar una determinación: "si robaste una vez, eres un ladrón". Es decir, se etiqueta, se juzga y se condena a las personas partir de una conducta.

La desintoxicación en este sentido que nos permite asumir un estilo democrático para el manejo de la disciplina, se encuentra en la Tolerancia. Es decir, asumir la pluralidad del grupo de clase, sin temor a las diferencias y aceptarles a todas y todos como son. Esto nos permitirá no clasificarles de acuerdo con sus conductas, y por lo tanto cuando sea necesario corregirles, hacerlo refiriéndonos a su comportamiento y no a la persona como un todo.

No obstante, si ya las etiquetas existen se puede hacer el proceso para quitarlas, con el inconveniente de que permanece una marca que evidencia que alguna vez estuvo una etiqueta ahí. De manera similar a cuando se remueve un rótulo a una botella, y queda la goma allí por mucho tiempo, el proceso de arrancar etiquetas cognitivas es complicado, solo se logra paulatinamente, con aceptación incondicional. Tal y como lo propone Ellis (2000), la personas son valiosas simplemente porque existen. 


\section{Desintoxicante 7. No personalice las Conductas Perturbadoras de sus Estudiantes}

Asumir las conductas perturbadoras de las estudiantes y los estudiantes como un ataque personal puede resultar sumamente desgastante.

Así se menciona en el Centro Territorial de Recursos para la Orientación, Atención a la Diversidad, Interculturalidad y Convivencia de Castilla en España (2006) en uno de sus manuales de convivencia escolar, donde señala que las conductas perturbadoras son el reflejo de una o varias necesidades insatisfechas, son una manera de pedir ayuda y encontrar esa satisfacción. Puede ser una carencia en necesidades de supervivencia, afectivas, de control o autoestima.

Por ello, las conductas perturbadoras cumplen la función de obtener aquello que posiblemente puede satisfacer la carencia de la persona, como por ejemplo, afecto o atención. Entonces, más que personalizar estas conductas es necesario cuestionarse ¿cuál o cuáles pueden ser las necesidades insatisfechas de esta o este estudiante?

La práctica de la empatía es el desintoxicante más atinado para esta idea. Ponerse en el lugar de la otra persona, y recurrir al diálogo abierto es una forma de acercarse al alumno o la alumna y descubrir en forma paulatina las razones reales de su comportamiento y poder analizar alternativas de solución más eficaces, que simplemente enfrascarse en la idea de que "la tiene contra mí".

\section{Desintoxicante 8. Déle la dimensión adecuada a las Conductas Perturbadoras}

En otras palabras no minimice su importancia (estilo permisivo) pero tampoco maximice el hecho (estilo autoritario). Valorar la situación de forma balanceada permite la administración de los esfuerzos hacia asuntos que realmente demanden de nuestra mayor atención.

Poder discernir qué conductas o situaciones perturbadoras pueden solucionarse entre estudiantes y cuales realmente requieren de la presencia de la docente o el docente, nos dirige a un estilo democrático y equilibrado de administrar la disciplina, pues de esta manera el rol que se asume es menos directivo y más asesor o facilitador en la resolución del conflicto. 
Pensar que las conductas perturbadoras que se presentan en el grupo son catastróficas y horribles es muy similar a que una persona hiperactiva caiga en arena movediza; jentre más nos movamos en este pensamiento más rápido nos hundimos!

Cuando este tóxico cognitivo aparece, suele frenar todos los esfuerzos que se puedan hacer para manejar la disciplina, y poco a poco conducir al docente a un estilo permisivo, pues es posible que termine por pensar: "qué importa que me esfuerce por mejorar, la convivencia en mi aula no va a cambiar."

Para empezar el proceso de desintoxicación de la idea llamada por Naranjo (2004) como el tremendismo, el primer paso es reconocer que las conductas perturbadoras están sucediendo, para poder salir del pantano de la idea de "esto no puede estar pasando, no en mi grupo..., no en mi escuela...", ya que pensar así inmoviliza cualquier acción y nos traga. Una respuesta más racional sería "esto está sucediendo, me gustaría que fuera de otra manera pero no lo es". Una vez aceptada esta situación es necesario reconocer la magnitud del evento, sin caer en los extremos. Una cosa es decir: "es lo que pasa en esta aula es insoportable..." y otra es decir por ejemplo, que "es incómodo lo que está sucediendo pero debemos afrontarlo".

Una vez realizados los anteriores dos pasos existen mayores probabilidades de que se encuentren soluciones a las conductas perturbadoras que están interfiriendo en el proceso educativo. Hay que recordar que no necesariamente todas las conductas perturbadoras pueden ser abordadas por las docentes y los docentes, existen algunas que requieren la intervención de otros profesionales de ayuda, en quienes es importante que el profesorado busque apoyo. Igualmente, reconocer que las estudiantes y los estudiantes no cambiarán del todo sus conductas, es necesario para la salud mental y emocional de las docentes y los docentes, en especial cuando se asume que debemos resolver los conflictos de todas las personas.

Se puede afirmar entonces, que el estilo democrático de disciplina es un estilo saludable para las docentes y los docentes. Al mismo tiempo su aplicación requiere de mucha autoevaluación y de la práctica de sus creencias racionales, para obtener el efecto deseado en el manejo de la disciplina para la convivencia escolar. 
En resumen, el estilo democrático se encuentra cognitivamente desintoxicado porque:

1. Busca la autonomía del estudiantado.

2. Considera las necesidades e intereses del grupo.

3. Procura la justicia, la equidad y la participación de todas y todos sus miembros.

4. Acepta incondicionalmente a las personas del grupo, aunque no necesariamente sus conductas.

5. Es flexible ante la normativa.

6. Es abierta al cambio.

7. Reconoce que los errores suceden pero son parte del proceso de aprendizaje.

8. No etiqueta a las estudiantes y los estudiantes.

9. No asumen las conductas perturbadoras como ataques personales.

10. Otorga a las conductas perturbadoras la magnitud adecuada (no minimiza ni maximiza).

\section{Conclusiones}

Luego del proceso de análisis del presente ensayo puede concluirse que:

La revisión de los estilos de disciplina desde la Orientación utilizando los enfoques cognitivos, brinda un elemento teórico aplicado a la convivencia escolar, que podría contribuir con procesos reflexivos en los centros educativos acerca de la vivencia del manejo de la disciplina.

Por otro lado, al abordar esta temática desde esta perspectiva de la Orientación Cognitiva, es evidente que para analizar la manera en que se gestiona la disciplina en las aulas y en las escuelas en general, es requisito una revisión personal de quienes administran el control en las instituciones de enseñanza.

Podría concluirse también que, si desde la Orientación se quiere ayudar al cambio en el manejo de la disciplina, hacia un estilo más democrático o ecuánime, es menester empezar por facilitar a las docentes y los docentes procesos de autoevaluación. 
Los estilos autoritarios y permisivos, se caracterizan por una serie de pensamientos automáticos disfuncionales que interfieren directamente en el clima escolar.

Dentro de las ideas irracionales abordadas en el análisis destacan por su influencia en los estilos de disciplina las siguientes: las falacias de control (junto a la resistencia al cambio), debo ser una persona aceptada y querida por las demás, los extremos, la rotulación y la catastrofización o tremendismo.

Es necesario concienzar en las docentes y los docentes que no todas las conductas o situaciones perturbadoras pueden ser abordadas por ellas y ellos, por dos razones en concreto:

1. existen situaciones y conductas que entre las estudiantes y los estudiantes pueden ser resueltas. Lo que hay que propiciar en ellas y ellos son espacios de formación en habilidades para la resolución de sus conflictos y así propiciar el crecimiento personal y un aprendizaje verdaderamente significativo. Lo cual, coloca a las docentes y los docentes, en una posición asesora del proceso de enseñanza y aprendizaje.

2. Hay situaciones y conductas perturbadoras que para ser resueltas positiva y sanamente es necesario que sean abordadas por profesionales de ayuda. Recurrir a estas profesionales y estos profesionales, es parte de las actitudes más saludables mentalmente que puede asumir una maestra o maestro.

No todas las estudiantes y no todos los estudiantes, luego de procesos de intervención o acciones para ayudarle a corregir sus conductas las cambiarán. Aceptar que esta posibilidad puede presentarse evitará en muchas docentes y muchos docentes y profesionales de ayuda, sentimientos de frustración y les mantendrá mentalmente más sanos.

Por último, se desprende del anterior análisis que la mayor parte del tiempo no se presentan los tres estilos de disciplina en su forma pura. En ocasiones puede haber docentes que tienden más hacia un estilo pero con matices de los otros. Por ejemplo, docentes que se inclinan hacia un estilo más autoritario pero en ocasiones pueden mostrarse más democráticos. También quienes tienden hacia lo permisivo a veces pueden manifestarse 
más democráticos o autoritarios. Asimismo docentes más democráticos que en algunas oportunidades pueden comportarse de manera más autoritaria o permisiva.

\section{Referencias}

Acosta, Alberto. (2007). Material para la Mejora de la Convivencia Escolar: Normas de Convivencia. Andalucía: Consejería de Educación y Ciencia. Dirección General de Orientación Educativa y Solidaridad. Recuperado el 3 junio de 2008, de http://www.juntaandalucia.es/averroes

Barba, María José, Lavigne, Rocío, Puerta, Susana, Portillo, Remedios, Rodríguez, Gemma (2002). Estilos Educativos y Conductas Adictivas. Recuperado el 15 de julio de 2008, de http://www.juntadeandalucia.es/averroes/ 29070180/Documentos/estilose.pdf

Baumrind, Diana. (1971). Current patterns of parental authority. Developmental Psychology Monograph, Part 2, 4 (1), 1-103.

Beck, Judith. (2000). Terapia Cognitiva. Conceptos básicos y profundización. Barcelona: GESIDA.

Centros Territoriales de Recursos para la Orientación, Atención a la Diversidad, Interculturalidad y Convivencia de Castilla en España. (2006). Convivencia Escolar: Centros Docentes. Recuperado el 158 de julio de 2008 de: http://www.deciencias.net/convivir/guias1/Convivencia_escolar(CastillaLM2006)74p.pdf -

Cubero, Carmen, Abraca, Angelina, Nieto, Marisol. (1996). Percepción y Manejo de la Disciplina en el Aula. San José: INIE. Universidad de Costa Rica.

De la Mora, Claudia. (2003). Disciplina en el Aula. México D.F.: Aula Nueva.

Ellis, Albert. (2000). Vivir en una sociedad irracional. Barcelona: Paidós.

Fierro, Cecilia y Carbajal, Patricia. (2003). Mirar la Práctica Docente desde los Valores. México: GEDISA

Fernández, Isabel. (1998). Prevención de la Violencia y Resolución de Conflictos: El clima escolar como factor de calidad. Madrid Narcea.

Naranjo, María Luisa. (2004). Enfoques Conductistas, Cognitivos y Racional Emotivos. San José: Editorial de la Universidad de Costa Rica.

Noller, Patricia y Callan, Víctor. (1991). The adolescent in the family. Londres: Routledge. 
Rabazo, María José. (1999). Interacción Familiar, Competencia Socio-Escolar, y Comportamiento Disocial en Adolescentes. Tesis Doctoral. Recuperado el 15 de julio de 2008, de http://www.pcid.es/public.htm

Riso, Walter. (2006). Terapia Cognitiva: fundamentos teóricos y conceptualización del caso clínico. Bogotá: NORMA

Riso, Walter. (2008). El Poder del Pensamiento Flexible. Bogotá: NORMA.

Rozemblum, Sara. (1998). Mediación en la Escuela. Resolución de Conflictos en el Ámbito Educativo Adolescente. Bueno Aires: Aiqué.

Tuvilla, José. (2005). Convivencia Escolar y Resolución Pacífica de Conflictos. Andalucía: Consejería de Educación y Ciencia. Dirección General de Orientación Educativa y Solidaridad. Andalucía. Recuperado el 3 junio de 2008, de http://www.juntaandalucia.es/averroes 